\title{
Duelo à Lua - o Sarrabal contra o Cego, cerca de 1740 -
}

\author{
Duel under the Moon - "Sarrabal" versus \\ the Blind Man, circa 1740 -
}

João Luís Lisboa

CHAM / NOVA FCSH

\section{DoI}

https://doi.org/10.37508/rcl.2021.n46a461

\section{RESUMO}

Os almanaques sempre publicaram textos que nasciam de provérbios ou de fantasias, da observação do quotidiano à vontade de rir e fazer rir. Neste artigo discute-se o papel que a leitura foi tendo, bem como a relação entre opções gráficas e textuais, através de alguns exemplos concorrentes. Nestes exemplos, duas personagens imaginárias (tipos reconhecidos do universo dos lunários), o Sarrabal Saloyo e o Cego Astrólogo, disputam a atenção dos leitores.

Palavras-chave: Lunário; sarrabal; humor; prognóstico; almanaque.

\section{Abstract}

The almanacs have always published texts that were born from proverbs or fantasies, from the observation of daily life to the desire to laugh and make people laugh. This article discusses the role that reading has played, as well as the relationship between graphic and textual options, through some competing examples. In these examples, two imaginary characters 
(recognizable types from the lunar universe), the "Sarrabal Saloyo" and the Blind Astrologer, compete for the readers' attention.

KEYWORDS: Lunarium; "sarrabal”; humour; prognosis; almanac.

"Meu pay e eu bastantemente nos accusamos, nos maltratamos, e nos satyrizamos, e assim nos querem, e comprão as nossas obras com gosto, ainda os que nos não conhecem: pello que peço a todos, digam mal das nossas prosas, abominem os nossos versos, cuspão os nossos prognosticos, e que nos tenham pelos mais nescios do mundo, que o nosso principal cuidado he o agrado commum, porque este he o que recoze os desgarros do vestido, e apaziga os gritos do estomago."

O Cego Astrologo Lisboa, Officina de Miguel Rodrigues, 1741, p. 9-10.

Calendários e previsões ajudam a organizar as tarefas do ano, antecipam as fadigas, anotam as festas, autorizam esperanças. Tudo parece muito prático, directo, útil, claro e, certamente, repetitivo. Esta é a tradição e a fortuna de muitos milhares de folhas, publicadas ao longo dos séculos na Europa e a que, em Portugal, se chamou reportórios, lunários, almanaques, prognósticos. Entrando pelo século XIX, foram-se reduzindo as partes de calendário e previsão e aumentando as de entretenimento e cultura geral. Cresceu a componente narrativa, em contos, poesias, anedotas, até se transformar num objecto diferente. Mas já antes dessa orientação oitocentista, o texto tinha o seu lugar entre outros elementos, símbolos gráficos, desenhos e números. Sempre se produziram textos que nasciam de provérbios ou de fantasias, da observação do quotidiano à vontade de rir e fazer rir. Nas páginas que se seguem, discute-se o papel que a leitura foi tendo, bem como a relação entre opções gráficas e textuais, através de alguns exemplos concorrentes. Em concreto, duas personagens imaginárias (tipos reconhecidos do universo dos lunários), o Sarrabal Saloyo e o Cego Astrólogo, disputam a atenção dos leitores. 
Se as críticas são um espelho do que se observa, podemos conhecer um pouco da atracção por estas folhas, em meados do século XVIII, através de um assumido Anti-reportorio, ou impugnação dos reportorios, de $1759^{1}$. Aí se pretende enfrentar o leitor que, todos os anos, deseja ter o seu exemplar, procurando vaticínios, gastando os seus vinténs "na compra dos almanaques de Damião Francês, de Manuel das Violas, do Hermitão da Senhora da Hora, e d'outros ignorantes (...)” (Anti-reportorio, 1759, prologo). Admite-se, além disso, que esse não é um leitor excepcional, mas o leitor comum. Daí que, recorrendo a argumentos científicos e a autoridades religiosas, o crítico assuma a empresa de abater quatro moinhos. $\mathrm{O}$ da validade de prognósticos sobre sucessos da vida humana, o da validade de prognósticos sobre o tempo, o da utilidade destas folhas para os trabalhos agrícolas e o da vantagem da sua leitura para a saúde.

A ideia de espelho serve-nos, não no sentido de representação realista, mas de inversão de perspectiva a partir de pontos de referência comuns. Assim se dá como plausível o sucesso reconhecido, os nomes que correm nas folhas, de que o de Damião Francês é talvez o mais frequente, mas também aqueles quatro pilares do interesse dos leitores que o crítico pretende derrubar. Os dois últimos são os que, no essencial, sustentam a convicção de utilidade dos almanaques, através da transmissão de conselhos prudentes e razoáveis sobre práticas e higiene. O crítico é implacável na denúncia da falsidade e da ignorância desses conselhos, e não apenas do erro genérico que, nestas folhas, associa movimentos cósmicos a fenómenos terrenos. De realçar a brevidade da crítica dirigida aos conselhos sobre a agricultura, em que o alvo não é tanto o erro, mas a repetição, e a inutilidade de se voltar a escrever o que já se sabe. Desvaloriza-se ou ignora-se, pois, o papel social dos calendários e

1 Anti-reportorio, ou impugnação dos reportorios, Porto, Oficina de Francisco Mendes, 1759. 
como a repetição é expediente que orienta e localiza. Despreza-se a corrente proverbial e a história antiga de calendários manuscritos, muitos dos quais, antes da imprensa, se apoiavam na repetição de imagens e de lugares comuns².

Quanto aos outros dois pilares a abater, remetem para a não validade de prognósticos, seja os que tratam da vida de cada um (o primeiro), seja os que antecipam os fenómenos atmosféricos (o segundo). Tudo muito racional, tudo muito sério, excepto quando se mobilizam exemplos. Efectivamente, a tradição das denúncias da falsidade de prognósticos assenta em exemplos que mostram, mais do que os falhanços das previsões, os seus lados absurdo e cómico, os jogos de evidências e de probabilidades equivocadas, o adivinhar-se o que já existe, confrontando-se o lugar comum e o expectável. Conta-se aqui o caso do Papa Alexandre VI, cuja morte foi prevista pelos “prognósticos” em 1495, e anos seguintes, até que, em 1503, rendidos à sua longevidade, "lhe prometterão huma vida dilatadissima, quando esta finalizou no mesmo anno"3.

O elemento de comicidade, recorrente no exemplo, parece estranho tanto à crítica como ao prognóstico criticado, que se levam muito a sério. E, no entanto, é elemento fundamental em casos muito conhecidos, como os dos almanaques de Rabelais, de que se publicaram sucessivas edições e adaptações a partir da sua Pantagrueline Prognostication, certaine, véritable et infalible ["sic") pour l'an mil DXXXIII 4.

2 Ver por exemplo um Calendário desdobrável, manuscrito e desenhado em Utrecht, 1397, hoje conservado no Deutsches Historisches Museum, em Berlim. 3 Anti-reportorio, ou impugnação dos reportorios, p.6.

4 Ver Raphaël Cappellen, "François Rabelais, Almanach pour l'an M.D.XXXV, texte découvert et édité par Alessandro Vitale-Brovarone", Cahiers de recherches médiévales et humanistes. Disponível em: http://journals.openedition.org/ crm/13505 ; DOI: https://doi.org/10.400o/crm.13505. 
Interessa interrogar se a troça, a escatologia, os estereótipos regionais e o absurdo destes prognósticos não cumprem afinal também algumas funções do calendário, quando pontuam os momentos do ano, com as suas festas e cuidados. Mas também quando sublinham, com o riso, aquilo que se repetia e que se repete ainda, cada vez que alguém volta a dizer que é melhor ser rico e saudável do que pobre e doente, e se adivinha que venham a morrer mais pessoas doentes do que pessoas saudáveis. Prever que o toucinho fugirá do grão na Quaresma marca as obrigações do calendário. Prever que, por falta de calças, haverá "colhões pendurados", mantém o jogo sem o calendário's Se tudo isto for servido com muitas referências a planetas, evidencia-se a auto-ironia do aparato. Ou seja, organizar é compatível com divertir, e essa convergência tem uma longa tradição.

No exemplo de Rabelais, como também no Sarrabal e no Cego de meados do século XVIII, a troça é evidente, mas por vezes é pouco clara a fronteira entre o que é apenas troça e o que é um calendário sério, e o antagonismo perde-se. Os santos, festas e luas estão nos seus dias próprios. Os conselhos são da ordem do bom senso. O calendário é útil. É certo que grande parte dos almanaques se leva muito a sério, e que os críticos nem sempre têm sentido de humor. Mas a auto-ironia permite manter um corpo central de elementos próprios destas folhas que continua a responder ao que os leitores procuram nos calendários, acrescentando-lhes elementos de atracção. Os intróitos continuam autorreferenciados, mas incluem a sátira. O que é pesado torna-se ligeiro. O que tantas vezes foi irritação motivada pela concorrência torna-se chiste. Mas isso apenas é possível para quem procura calendários sem dar muita importância às previsões, porque o crédulo é insultado. Se ao leitor agrada e serve o folheto, este assume que a carapuça não lhe

5 François Rabelais, Almanaques e prognósticos, Porto, Campo das Letras, 1995 , p 37. 
serve. É aí que os textos ganham um lugar próprio. O útil junta-se ao divertido, nos almanaques, que assim podem ao mesmo tempo entreter, divertir, e orientar.

Essa convergência de funções e motivos de atracção é recorrente, numa competição onde com frequência não se distingue o jocoso e o sério, em edições sucessivas de folhetos, e a utilização no título da palavra "jocosério" orienta os compradores e serve de chamariz ${ }^{6}$. Por vezes, a sátira é evidente, como neste folheto manuscrito, provavelmente de 1734, onde se lê:

Pronostico serio do anno 1735, Lunario rustico calcullado em a Aldeya de muytos ventos, meridiana de Lisboa occidental pellos milhores observantes aunque mortos, com o juizo geral deste prezente anno de 1735 e suas quartas, e declaraçoins das origens dos mezes, escripto por hum rustico Anacoretta, nas cazas de sua morada. Autor oculto, conhecido só de q(ue)m o ignora. Sem licenças, mas pellos Velhos approvado. Na oficina $d(e)^{7}$

Aquilo que se nota nos poucos manuscritos que sobreviveram torna-se evidente na multidão de impressos. Tomemos o ano de 1736, quando temos acesso a pelo menos seis publicações de quatro impressores diferentes, Manuel Fernandes da Costa, Miguel Rodrigues, Pedro Ferreira e Pedro de Sousa Vilella.

6 Ver Lisboa, J.L., 2002: "Almanaques" in Os sucessores de Zacuto. O almanaque na BN do século XV ao XXI, Lisboa, Biblioteca Nacional, p. 11-23; e Curto, D. R, "Almanaques e prognósticos" in História política da cultura escrita, Lisboa, Verbo, 2015, p. 183-223.

7 Biblioteca Nacional de Portugal, COD. 2113. 
1736, Prognostico prozopoetico, fabulogico, jocoserio, metaforico para o anno de 1737, Endimião Portuguez, Lisboa Occidental, Off. de Manoel Fernandes da Costa, Impressor do Santo Officio.

1736, Prognostico geral para o anno de 1737, primeyro depois do bissexto, O grão pescador Cosme Francez Sarrabal Saloyo, Lisboa Occidental, Officina de Miguel Rodrigues.

1736, Prognostico curioso : para o anno de 1737... : recopilado das doutrinas do Sarrabal e afforismos de graves authores., composto por Balthasar do O, Lisboa Occidental, Off. de Pedro Ferreira. 1736, Prognostico e curioso sarrabal para o anno de 1737 primeiro depois do bissexto, por Crispim Roberto Reimam, Lisboa Occidental, Officina de Miguel Rodrigues.

1736, Prognostico e curioso sarrabal para o anno de 1737, por Rodrigo de Souza Alcaforado, Lisboa Occidental, Officina de Felippe de Sousa Villela.

1736, Prognostico para o anno de 1738, Cego Astrologo Antonio Pequeno, filho bastardo do Sarrabal Saloyo, Lisboa Occidental, Off. de Miguel Rodrig(ues), Impressor do S. Patriarca.

Miguel Rodrigues, um dos mais activos e plurifacetados impressores da época, está em destaque publicando três títulos concorrentes, um do Sarrabal Saloio, um de Crispim Reimão e outro do Cego Astrólogo. Ou seja, a oficina do Cardeal Patriarca empenha-se em fazer publicações alternativas, sérias e jocosas. Não sabemos até que ponto a iniciativa é do impressor, ou se se limita a acolher ideias de quem se dedica a este género e, dado o historial de Miguel Rodrigues, são plausíveis ambas as possibilidades. Quando de uma mesma oficina saem produtos diferentes, há que prestar atenção a essas diferenças. Como se disse, pretendemos centrar-nos no confronto entre o Sarrabal Saloio e o Cego Astrólogo, duas referências emblemáticas e repetidas, ao longo de pelo menos uma dezena de anos. 
As referências autorais são parte de uma mesma constelação, membros de uma família imaginada por onde começa a ficção dos almanaques. Os vários “autores” emblemáticos apresentam-se como filhos e primos, o que os faz pertencer ao mesmo mundo. São emblemas que troçam de emblemas, servindo-se deles, estereótipos que se desmascaram, mascarando-se. O Sarrabal tem um nome, Cosme Francês, “irmão gémeo” do muito conhecido Damião Francês, autor também ele emblemático de prognósticos de que acima se falou, naturais de Vilar de Frades, pormenor que sustenta uma autenticidade rural. Já o Cego Astrólogo chama-se António Pequeno e é “filho bastardo" do Cosme Francês e, portanto, sobrinho do Damião. O Cosme e o seu filho António serão sempre publicados a par. Completam-se e discutem. Existem para serem comprados por uns e por outros, embora também apontem para opções e públicos distintos.

A pertença por via dos nomes próprios é apenas um dos elementos de identificação. Mais importante, na construção ficcional da dupla, é o que significa ser Sarrabal Saloio e Cego Astrólogo. O termo "Sarrabal" podia designar tanto o folheto como o fazedor do folheto, o que é o caso justamente deste Cosme Francês que se apresenta como Sarrabal Saloio, irmão do Damião Francês (fig.1). O termo tinha-se afirmado no imaginário deste género alguns anos antes, como importação e sinónimo de lunário sério, como se lê em exemplos explicitando a referência ao "sarrabal milanez" ${ }^{8}$. Este sarrabal é o "Grão

8 Exemplos, de 1728 e 1729, de dois impressores diferentes: Prognostico, e lunario perpetuo, tirado das doutrinas do Sarrabal Milanez, calculado do meridiano das nobelissimas cidades, e Corte de Lisboa, em quanto às lunações somemte; com os Eclypses, e noticia de seus effeitos, composto pelo P. Mestre Fr. Theobaldo de Jesu Maria, Lisboa Occidental, Officina de Joseph Antonio da Sylva, 1728; Almanaque lusitano do anno de 173o. segundo depois do bissexto para todo o reyno de Portugal e suas conquistas em que se segue a doutrina, e o methodo do Sarraval Milanes, e se observa o meridiano da insigne cidade de Lisboa, por Innocencio Fernandes de Coura, Lisboa Occidental, Officina de Manoel Fernandes da Costa, Impressor do Santo Oficio, 1729 . 
pescador" que reproduz o "Gran Pescatore" italiano e o "Gran piscator" espanhol, ambos sarrabais, e tanto pode ter vindo directamente de calendários italianos ${ }^{9}$ como, mais provavelmente, de forma indirecta através de apropriações espanholas desses termos, sempre mantendo a matriz lombarda e a origem milanesa ${ }^{10}$.

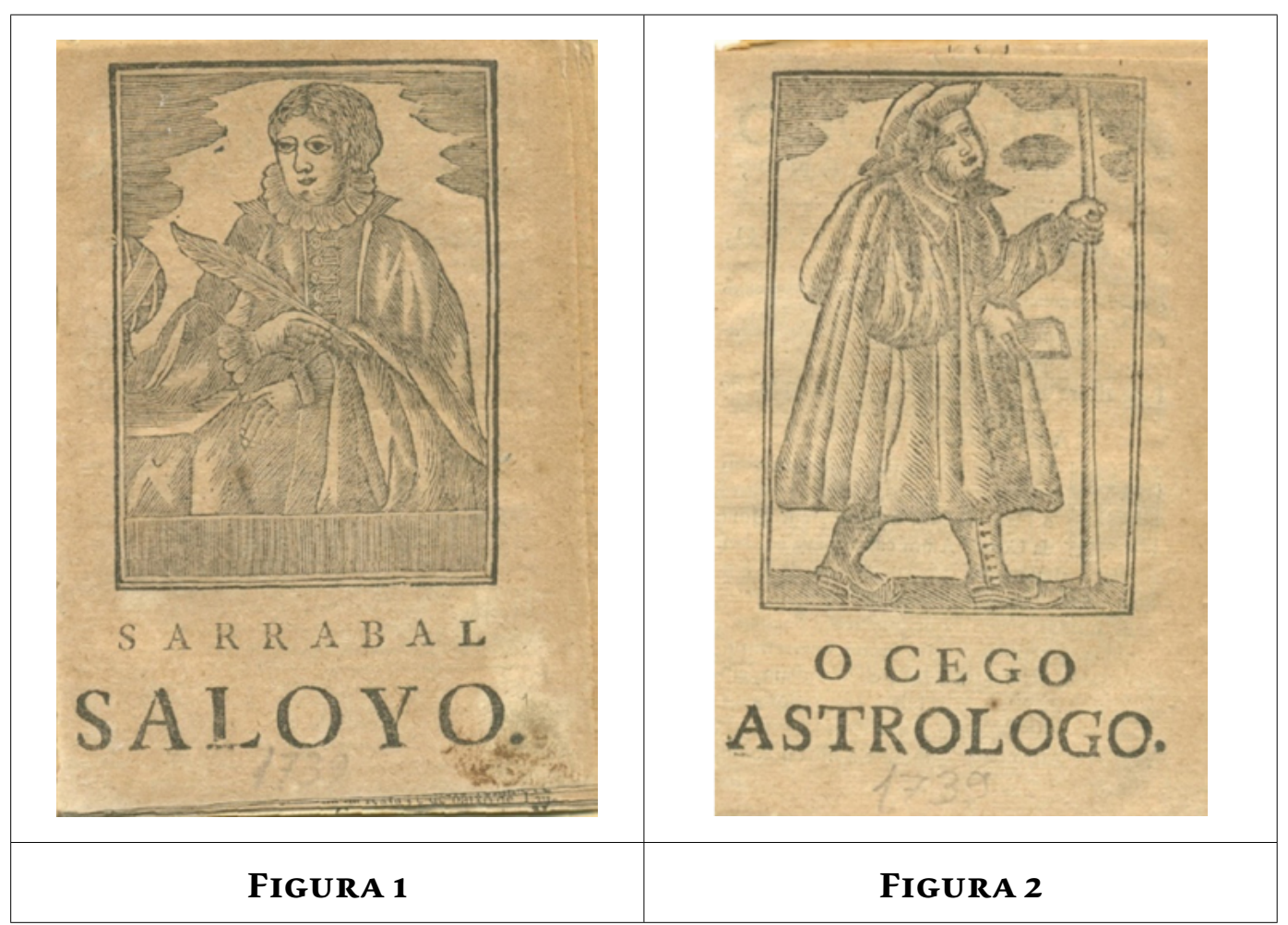

Seguimos palavras e objectos como parte de um tráfico rendoso do sul da Europa. O termo "sarrabal" continuava a correr nos finais do século, a par do de "lunário". Embora já não usado pelos impressores,

9 Almanacco universale sopra l'anno ... del Gran Pescatore di Chiaravalle, Milão, Officina de Lodovico Monza (e, posteriormente, outros), 1681 e seguintes. Ver, Cerati, Piero e Bizzarri, Corrado, Il gran pescatore di Chiaravalle : almanacco popolare, Collegno : G. Altieri, 1998.

10 Pronostico y almanac universal, sobre el año 170o, Gran Piscator Sarrabal, A los Algodoneros, Officina Rafael Figuerò, 1700. 
era ainda reconhecível, a julgar pelos versos de Miguel Couto Guerreiro, um moralista da segunda metade do século XVIII que, entre outros, ataca os crédulos. Essa gente que, além de acreditar em vampiros e unicórnios, segue o que dizem os almanaques:

Os sarrabaes tem nelle o seu patrono:

Quantas vezes de noite perde o somno,

Porque o seu Sarrabal lhe diz, que em Maio

Hão-de haver furacões, e muito raio?

Tem que ver, como está imaginario

A ler a sua sina no Lunario!.

Se prognostica bem, alegre rosto,

Se mal, ei-lo com cara de desgosto: ${ }^{11}$

Quanto ao Cego Astrólogo, junta duas personagens, o cego que vende as folhas na rua e o sábio que conhece os astros. Incapaz de ver os movimentos dos astros, calcula-os. Menos importante do que a verosimilhança era o reconhecimento. A gravura da primeira página, reproduzida todos os anos, embora mais rudimentar, é semelhante às que, já no século XIX, mostram o cego apregoando os seus papeis (fig.2) $)^{12}$.

A diferença social que a gravura evidencia, apesar de alegadamente serem pai e filho, tem outra expressão no interior. O formato 10x15 é comum aos dois títulos, variando os dois entre as 30 e 40 páginas, mas enquanto cada página do Sarrabal tem 38 linhas apertadas, de

11 Miguel do Couto Guerreiro, Sátiras em desabono de muitos vícios, Lisboa, Francisco Luís Ameno, 1786, p. 88. Ver, Leite de Vasconcelos, "Tradições Populares Portuguesas do Século XVIII contidas nas poesias impressas de Miguel do Couto Guerreiro", Revista lusitana, vol. VI, 1900, p. 273-299. Sobretudo p. 287 e 292.

12 Sobre a figura e instituições dos cegos papeleiros, também em Portugal, ver Abel Iglesias Castellano, "Entre la voz y el texto. Los ciegos oracioneros y papelistas en la España moderna (1500-1836)", Doctorado en Historia, DHF, Facultad de Filosofía y Letras, Universidad de Alcalá, 2018. 
letra pequena, o Cego, com uma letra um pouco maior, não ultrapassa as 31 linhas. Têm, assim, condições de leitura completamente diferentes e, normalmente, tem mais texto o Sarrabal do que o Cego. Nas figuras 3 e 4 são manifestas as diferenças no tipo de letra e na legibilidade das páginas do Sarrabal (fig.3) e do Cego (fig.4), para o mesmo mês de março de 1739 .

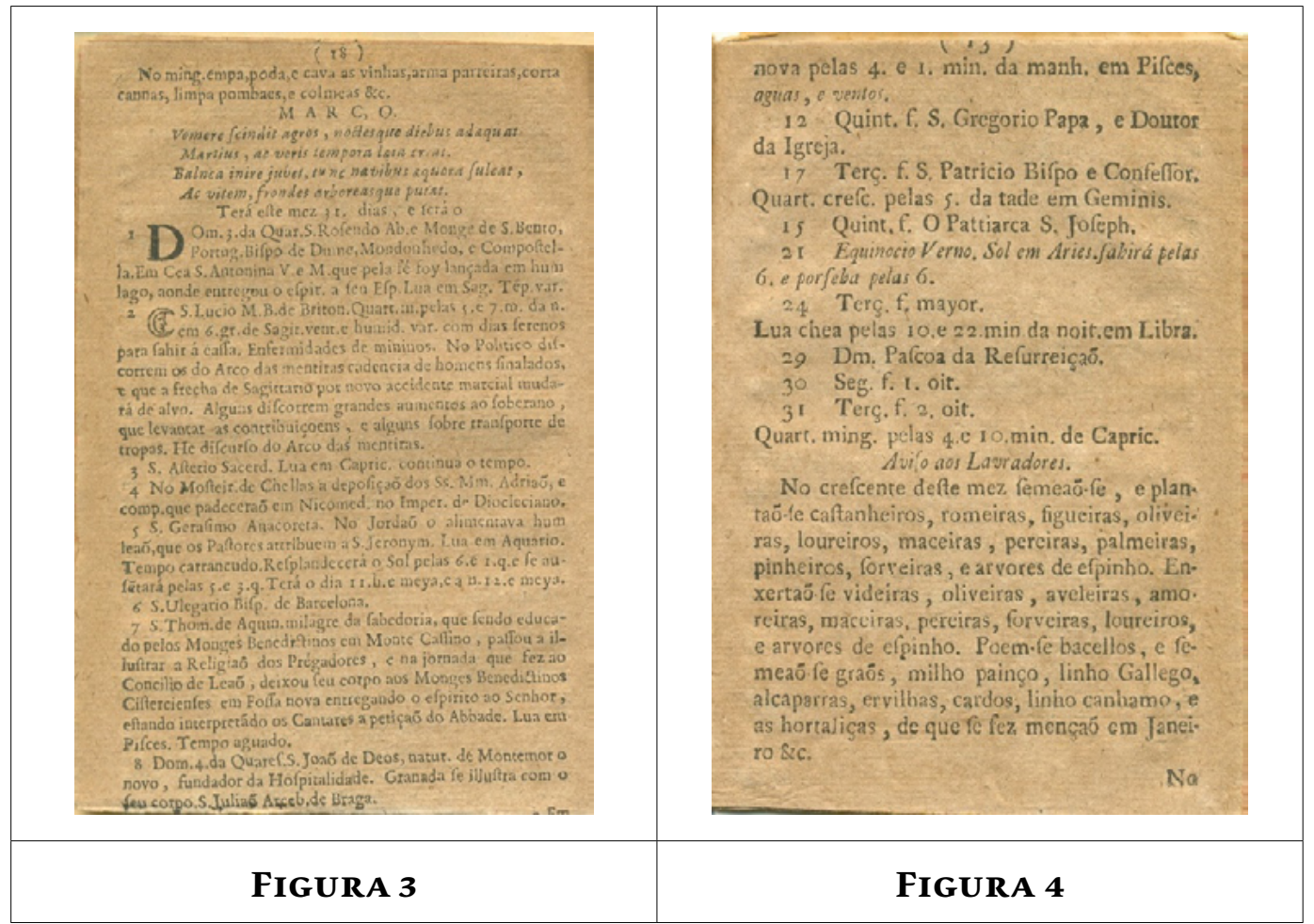

A leitura do calendário é simples, ajudada por expedientes gráficos, como cruzes destacando algumas efemérides religiosas e pequenas luas (cheias, decrescentes, novas e crescentes) nos dias próprios, o que não evita imprecisões ou erros. Cada folheto tem a numeração das páginas a contar da folha que ilustra e que, por isso, funciona como uma autêntica capa, num tempo em que essa distinção ainda não existia. Por isso, as páginas 2 ou 3 podem ostentar título e configurar-se como folhas de rosto, incluindo informação sobre os anos a que o calendário se reporta e a paginação aparecer a seguir, come- 
çando da página 3 ou 4. O nome do impressor Miguel Rodrigues está com frequência no fim do folheto, mas também pode estar na página 3, quando esta passa a ser uma folha de rosto, ou pode nem sequer estar presente, embora, pelo material gráfico, se perceba que se trata sempre da mesma oficina. Além do tamanho de letra e a densidade da mancha gráfica, o duelo entre estas folhas faz parte de uma ficção que se pretende bem disposta.

A estrutura dos dois folhetos é semelhante. Compreende uma introdução (entre 3 e 8 p.), onde se conta uma história que pretende divertir, por vezes incluindo versos, de seguida um juizo sobre o ano que está para começar (1 a 4 p.), um "cômputo" com as datas principais do ano, em meia página, um calendário por meses e dias, com previsões, avisos para lavradores, textos intercalados e prognósticos ou conselhos no fim. Por vezes inserem-se outras pequenas rubricas, algumas efemérides históricas e sagradas, sonetos, epigramas, "advertências curiosas" no final e algumas linhas de despedida.

Estamos no início de 1739. Cego e Sarrabal publicam as suas folhas. As páginas de introdução, zona primeira da construção ficcional e de apresentação, são muito diversas, embora cumpram, as duas, um papel de autoreferenciação, e de apontamentos do quotidiano em que os lunários circulam. O Cego abre com uma situação cómica, descrevendo a sua fuga perante uma mulher que queria com ele casar, no momento em que apregoava pelas ruas os seus "saloyo crítico, o Damião com credito e o Mono da Corte” (O Cego, 1739, p. 2). A aversão ao casamento é aliás um tópico que acompanha a personagem noutros anos. O Sarrabal, por seu lado, expõe argumentos de autoridade para justificar o tempo que gasta com a astrologia e os prognósticos, sempre dizendo

troquemos por bom dinheiro este falso, ou esta falsidade, e esperemos pelos que atribuem os embustes com que exornamos as suas quadras por satisfazer ao costume dos tontos a adivinhaçoens, pois não ignoramos que os sinaes celestes dispostos para 
significarem, de nenhum modo offendem a nossa liberdade. ( $O$ Grão Pescador, 1739 p.4).

Estes dois intróitos anunciam o juizo para 1739. O juízo de sarrabal enche quatro páginas de uma ostentada falsa erudição que, mencionando muitas localizações astrais, refere o que é evidente e o que é impossível de saber. Remata assumindo:

Acabou-se a prognosticação do anno, divertimento para a nossa ociosidade. O juizo que della se deve fazer he ser hum deliramento engenhoso, pois estou certo que eu à imitação dos mais escrevo o que da penna corre sem estudo, nem violencia, ainda que com apparente artificio, para gadanhar os vintens, de que necessito. Bem sei que muitas coisas ditas accaso podem tambem por accaso suceder." (O Grão Pescador, 1739 p.9).

Já o Cego, em duas páginas sem aparato coloca em Marte e Vénus as esperanças de "mais pão e mais barato, muita água e azeite, e muitas mentiras". (O Cego, 1739, p. 7-8). O Sarrabal Cosme expõe as estações do ano. O filho António faz prognósticos genéricos.

Quanto aos dias e aos meses, coincidem forçosamente nos santos e nas luas. Há que ter presente que crescentes e minguantes importam para orientar as actividades, dividindo em dois todos os meses, e essa é uma função básica dos calendários. Depois da lua nova de setembro, semear centeio, cevada e trigo em terras húmidas. Já depois da lua cheia desse mês, vindimar, colher e lavrar... (O Grão Pescador. Sarrabal para 1743). Mas é indiferente acertar com as posições relativas dos astros, se nos mesmos dias a Lua está sobre a constelação Balança ou Virgem e essas incongruências estão no Sarrabal e no Cego. De novo o Sarrabal é mais completo e desenvolvido, incluindo informação de efemérides históricas mas, inversamente, o Cego tem mais espaço para a secção “Avisos aos lavradores”, a secção mais "séria" nos dois casos. 
No final, ambos dão primazia ao que a Igreja ensina, reafirmando a sua pouca fé em prognósticos em geral e naqueles que eles próprios difundem em particular. O Sarrabal é de novo mais explícito, associando outros lugares comuns como o da natureza igualmente conjectural da Medicina. (O Grão Pescador, 1743, p. 40). Os lugares comuns sucedem-se e apoiam o sucesso pretendido para as publicações.

Reproduzindo o mesmo exercício para outros anos em que o confronto é possível, confirmamos as escolhas e estratégias de quem fazia estas folhas. Em 1742, o Sarrabal fala no seu intróito sobre melancolia na cidade, discorrendo sobre saber e crítica, sobre ambições e descontentamento, sobre tipos sociais e ociosidade, e sobre os leitores que ele, fazedor de prognósticos, imagina para os papéis que escreve. Quatro páginas de jogos de conceitos pontuadas por latinório e encerradas por um soneto. A melancolia serve-lhe para mais um jogo de palavras em torno do juízo, que não perdeu porque nunca teve, e que não usa como devia, na parte que se segue ao intróito (o juízo do ano). Essa parte está sem título e assim se entra directamente na descrição do inverno que virá e fica-se por aí, num breve trecho sobre a fragilidade do mundo. O intróito de Cego é mais longo em páginas, embora a quantidade de texto seja equivalente. Ao contrário da melancolia do Sarrabal, dedica-se à alegria de músicas e bailes, incluindo versos de canções populares. Em vez dos livros, temos as ruas de Lisboa.

Escrevo para o vulgo, porque a este he que devo informar para lhe sacudir o pó do espanto, e da ignorancia, e a este só quero contentar (ainda que os críticos me roão) porque este com seus vinténs me ajuda a passar a vida, e não cuido em que digam que estas obras nada valem, porque a boa venda he que ha de mostrar o seu valor. (O Cego, 1742, p. 9).

O juízo do Cego para 1742 é mais desenvolvido, parecendo substituir aquele que o Sarrabal quase não apresenta, dando destaque a 
previsões meteorológicas de acordo com as estações do ano. A hipótese de troca ou contaminação, provavelmente voluntária, é reforçada por dois indícios: a grafia "almanak", típica do Sarrabal, e aqui usada pelo Cego e a inclusão de efemérides históricas. A componente mensal e diária segue a regra geral, mais exaustiva a do Sarrabal, mais atenta aos avisos para lavradores o Cego, coincidentes em tudo o que seja matéria mais séria.

Duas personagens, dois estilos, duas opções de composição da página, eventualmente escolhas desencontradas de argumentos astrológicos, afinal o que menos importa porque, precisamente, tanto uma como outra assumem a sua pouca confiança na astrologia. $\mathrm{O}$ pai é o erudito que cultiva o artifício e recorre ao latim com frequência. O filho é um comediante muito simples que vive num ambiente de pátio popular. O pai sarrabal é culto e com pretensões, mas pobre. O filho cego goza a vida como vem, uma personagem que deve ser alegre e alegrar. Um é o humor elegante. O outro é grotesco. Duas fantasias, onde o leitor encontra as personagens nas suas actividades de fazedores e vendedores de prognósticos, nos seus quotidianos, nos seus pensamentos sobre o mundo e a matéria das suas folhas, a mentira e a imponderabilidade da vida. Um duelo fictício, entre personagens complementares, que reflecte bem a disputa dos vinténs que as folhas valem. E o que as folhas valem, e não o que elas custam, com o seu fundo comum, depende das suas diferenças, da variedade das histórias que contam, do espírito que mostram, da forma como usam as retóricas próprias a cada personagem e a cada grupo de leitores imaginados. Outras diferenças dependem mais das circunstâncias de cada ano, usarem ou não as pequenas gravuras para assinalar as fases da lua, por exemplo.

Um ponto de chegada, neste percurso, volta a juntar a tradição jocosa e céptica que vem pelo menos desde Rabelais. Os textos acrescentam valor, fazem a diferença, atraem, não apenas pela graça, mas também pela curiosidade e pela utilidade, como se tornará comum 
no século XIX. Veja-se a tabela acrescentada ao folheto do Cego Astrólogo para 1740, contendo mais de 120 nomes de plantas, com os significados respectivos, o abeto associado à contemplação, o buxo à inocência, e assim por diante. O duelo acrescenta e permite a variedade. Oferece o mais sério e o mais cómico em perfis distintos. Chama a atenção e, mesmo repetindo, consegue mais vendas durante anos a fio.

No mesmo folheto, as despedidas do Cego, como de costume, assumem o engano:

“(...) tudo o que digo, não tem mais estabelecimento, e certeza, que a de palavra de Astrologo, e cego, que he o mesmo que a de Alfayate, pelo que tem de mentira. Supponho, que não o estranharão vossas merces, pois estão bem costumados a estas patranhas, modo de garfiar vinteins dos escondrijos de sua avareza para remedio de Cegos, Impressores, e Astrologos, e a Deos até o anno, que vem, se lá chegarmos; e quando não, sempre a Deos”

O Cego Astrologoss.l., s.n., [1739] p.28.

RECEBIDO: $14 / 07 / 2021$ APROVADO: $24 / 08 / 2021$

\section{REFERÊNCIAS}

\section{Fontes:}

\subsection{Manuscrito:}

Pronostico serio do anno 1735, Lunario rustico calcullado em a Aldeya de muytos ventos, meridiana de Lisboa occidental pellos milhores observantes aunque mortos, com o juizo geral deste prezente anno de 1735 e suas quartas, e declaraçoins das origens dos mezes, escripto por hum rustico Anacoretta, nas cazas de sua morada.

Biblioteca Nacional de Portugal, COD. 2113. 


\subsection{Impressas:}

Almanacco universale sopra l'anno ... del Gran Pescatore di Chiaravalle. Milão: Officina de Lodovico Monza (e, posteriormente, outros), 1681 e seguintes.

Anti-reportorio, ou impugnação dos reportorios. Porto: Oficina de Francisco Mendes, 1759 .

O Cego Astrologo Antonio Pequeno (...) Prognostico particular para o anno de (...). Lisboa: Oficina de Miguel Rodrigues, exemplares dos anos 1738, 1739 e 1741 (o de 1739 sem referência de local, impressor e data).

Coura, Innocencio Fernandes de, Almanaque Lusitano do anno de 1730. segundo depois do bissexto para todo o reyno de Portugal e suas conquistas em que se segue a doutrina, e o methodo do Sarraval Milanes, e se observa o meridiano da insigne cidade de Lisboa, Lisboa: Officina de Manoel Fernandes da Costa, 1729.

GUERREIRO, Miguel do Couto. Sátiras em desabono de muitos vícios. Lisboa: Francisco Luís Ameno, 1786.

O Grão Pescador, Cosme Francês, Sarrabal Saloio (...) Almanack Geral para o anno (...). Lisboa: Oficina de Miguel Rodrigues, exemplares dos anos 1738, 1741 e 1742 (o último sem referência de impressor).

Maria, Fr. Theobaldo de Jesu, Prognostico, e lunario perpetuo, tirado das doutrinas do Sarrabal Milanez, calculado do meridiano das nobelissimas cidades, e Corte de Lisboa, em quanto às lunações somemte; com os Eclypses, $e$ noticia de seus effeitos,. Lisboa: Officina de Joseph Antonio da Sylva, 1728.

Pronostico y almanac universal, sobre el año 170o, Gran Piscator Sarrabal, A los Algodoneros, Officina Rafael Figuerò, 1700.

RABELAIS, François. Almanaques e prognósticos. Porto: Campo das Letras, 1995.

RABELAIS, François. Almanach pour l'an M.D.XXXV, texte découvert et édité par Alessandro Vitale-Brovarone. Paris: Classiques Garnier (" Les Mondes de Rabelais" 3), 2014.

\section{Estudos}

CASTILLO GÓMEZ, Antonio. Outros textos. Outras leituras. Divagações metodológicas em torno de efêmeros e papéis menores, Livro. Revista do Núcleo de Estudos do Livro e da Edição, 6, 2016, p. 351-364. 
CERATI, Piero; BIZZARRI, Corrado. Il gran pescatore di Chiaravalle: almanacco popolare, Collegno, G. Altieri, 1998.

CURTO, Diogo Ramada. Almanaques e prognósticos. In: CURTO, D.R., História política da cultura escrita. Lisboa: Verbo, 2015, p.183-223.

DURÁN LÓPEZ, Fernando. Juicio y chirinola de los astros. Panorama literario de los almanaques y pronósticos astrológicos españoles (17001767). Gijón: Trea, 2015.

IGLESIAS CASTELLANO, Abel. Entre la voz y el texto. Los ciegos oracioneros y papelistas en la España moderna (1500-1836). Doctorado en Historia, Departamento de Historia y Filosofía, Facultad de Filosofía y Letras, Universidad de Alcalá, 2018.

LISBOA, João Luís. Almanaques. In: Os sucessores de Zacuto. O almanaque na BN do século XV ao XXI. Lisboa, Biblioteca Nacional, 2002, pp. 11-23.

PABLO ZAMORA, Alba de. El repertorio del ciego coplero a través de la figura de Juan de la Cruz (1871-1960). Trabajo Fin de Máster, Universidad de Valladolid, 2013.

PAJÓN MECLOY, Enrique. El ciego como figura literaria. Madrid: Antígona, 2013.

PEÑA VELASCO, Concepción de la. Leer bajo el cielo: una imagen de lectura oral en el mundo rural a finales del siglo XVIII, Tonos Digital. Revista de Estudios Filológicos, 31, 2016.

RUBIO ÁRQUEZ, Marcial. Testamentos poéticos burlescos: hacia la definición de un subgénero literario popular. In: CÁTEDRA, Pedro M. Cátedra (dir.) et al. La literatura popular impresa en España y en la América colonial. Formas $\mathcal{E}$ temas, géneros, funciones, difusión, historia y teoría. Salamanca. SEMYR, 2006, p. 241-251.

SALMAN, Jeroen. Pedlars and the Popular Press. Itinerant Distribution Networks in England and the Netherlands. 1600-1850. Leiden-Boston: Brill, 2014.

SPERO, Patrick. The revolution in popular publications: The Almanac and New England Primer, 1750-1800. Early American Studies. An Interdisciplinary Journal, Volume 8, Number 1, 2010, p. 41-74.

VASCONCELOS, José Leite de. Tradições Populares Portuguesas do Século XVIII contidas nas poesias impressas de Miguel do Couto Guerreiro. Revista Lusitana, vol. VI, 1900, p. 273-299. 


\section{MinicurRículo}

João Luís Lisboa é professor da Nova FCSH (Departamento de História) e investigador do CHAM - Centro de Humanidades, da Universidade Nova de Lisboa, onde faz parte do grupo de investigação "Leitura e formas da escrita". 